Brit. J. Ophthal. (1953), 37, 54.

\title{
INFLUENCE OF THE THIRD CRANIAL NERVE ON INTRA-OCULAR PRESSURE*
}

\author{
BY
}

\author{
D. P. GREAVES AND E. S. PERKINS
}

From the Institute of Ophthalmology, London

Director of Research: Sir Stewart Duke-Elder

THE adrenergic sympathetic system has been shown to exert a considerable effect on the intra-ocular pressure (Greaves and Perkins, 1952). We know, however, that cholinergic drugs are often effective in lowering the intraocular pressure in glaucoma so that it is possible that the parasympathetic system may also play a part in the control of the tension of the eye. Since the third cranial nerve carries the parasympathetic supply to the intra-ocular musculature, it is logical in the first place to determine whether it is also responsible for the cholinergic control of the intra-ocular circulation.

The literature on this subject is small. Henderson and Starling (1904), after some careful experiments, concluded that the third cranial nerve had no effect on the intra-ocular pressure. Schmerl and Steinberg (1950) however, reported that electrical stimulation of the ciliary ganglion in the rabbit caused a rise, and cauterization of the ganglion caused a fall, in the intra-ocular pressure. They used a blind approach to

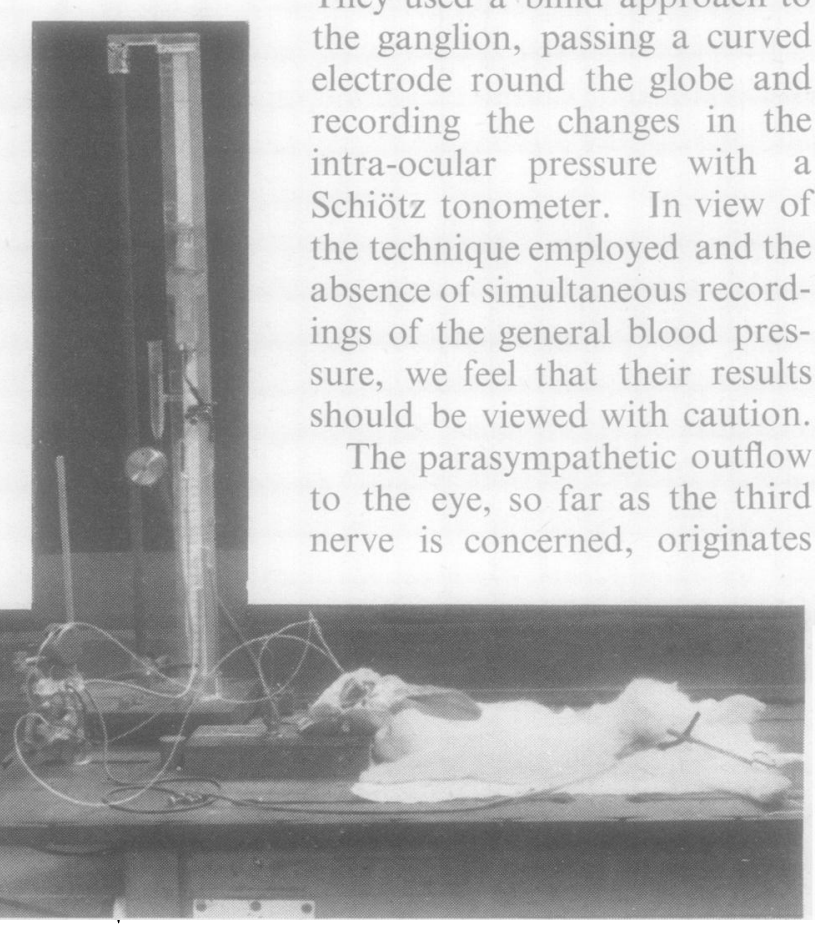


in the midbrain in close association with the nucleus of the third nerve, and travels along this nerve to the ciliary ganglion, whence it reaches the eye by way of the short ciliary nerves. In the rabbit the ciliary ganglion and orbital portion of the third nerve are relatively inaccessible without causing considerable upset to the vascular supply and venous drainage of the eye. We have therefore exposed the third nerve in its intracranial course, an approach which can be facilitated by decerebration.

\section{Methods}

Rabbits were anaesthetized with nembutal intravenously, 1 gr. per $5 \mathrm{lb}$. body weight. The skin and muscles were reflected off the cranium and the skull opened with a trephine. This opening was enlarged with bone nibblers until the cerebral hemispheres could be freed and either removed or elevated to expose the third nerves in their course on either side of the pituitary fossa. Bleeding from the circle of Willis was a frequent complication and great care was required to isolate the nerve without causing profuse haemorrhage.

The nerve could now be cut and stimulated by applying a bipolar electrode connected to an electronic stimulator giving a square wave, 50 cycles/sec. at 4 volts (Attree, 1950).

The intra-ocular pressure was measured by the manometer described in a previous paper (Greaves and Perkins, 1951) whereby simultaneous records of the intra-ocular pressure of both eyes and the general blood pressure were made.

Fig. 1 shows the general

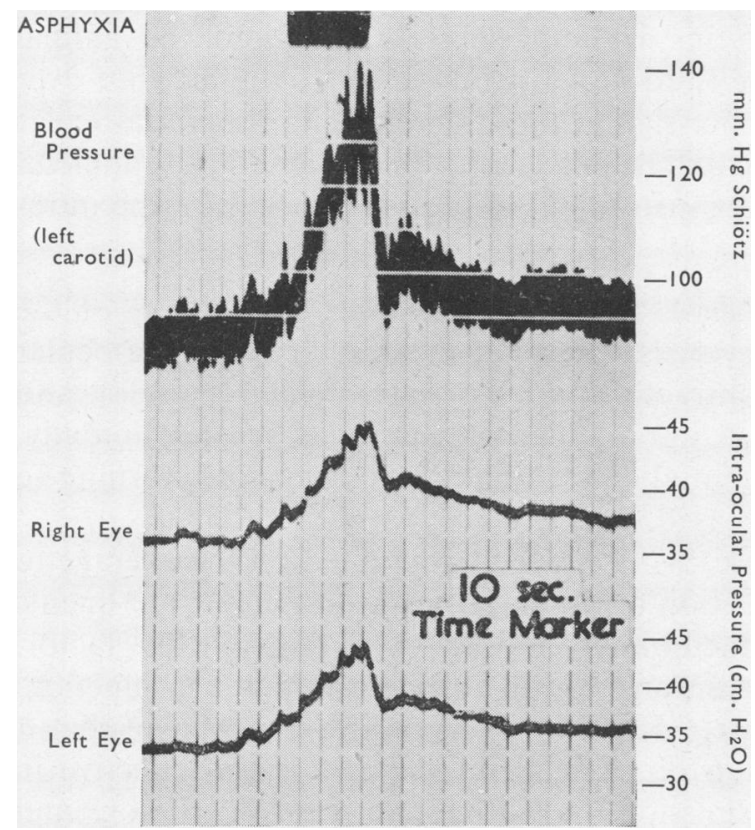

FIG. 2.-Typical tracing showing variations in intra-ocular pressure and blood pressure during asphyxia. arrangement of the apparatus. Fig. 2 shows a typical tracing made by this method and which illustrates well how the intraocular pressure varies with the general blood pressure.

\section{Results}

(1) Effects of Decerebration.-As decerebration was usually performed before the intra-ocular pressure and blood pressure tracings were started, it was thought advisable to do two control experiments in which the intra-ocular pressure and blood pressure were recorded during the actual procedure of decerebration so that any variation produced by the operation could be observed. In one of these experiments it was found that, apart from a temporary disturbance during the manipulations, the blood pressure and intra-ocular pressure soon settled down to their previous level. In the other experiment the blood pressure 
dropped by some $20 \mathrm{~mm}$. $\mathrm{Hg}$ with a corresponding fall in the intra-ocular pressure following a rather profuse haemorrhage from the circle of Willis. It would therefore appear that, provided severe haemorrhage can be avoided, decerebration has little influence on the results of the experiments. Further confirmation of this was given by three experiments in which the nerve was exposed without decerebration, the results differing in no way from those obtained in the decerebrate animal.

\section{(2) Section of the Third Nerve}

(a) Acute Experiments.-The intra-ocular pressure was observed for periods up to $30 \mathrm{~min}$. in each of four animals in which one or both third nerves had been cut. In two cases, no significant change in the intra-ocular pressure was observed. In one case section of the nerve was followed by a rise in the intra-ocular pressure. In this experiment haemorrhage round the nerve occurred during the exposure and section, and a plug of cotton wool which was used to stop the bleeding probably interfered with the venous return from the eye, for on its removal the intra-ocular pressure returned to normal. In another animal a slow fall of $2 \mathrm{~cm}$. saline was recorded.

(b) Survival Experiment.- In one rabbit the third nerve was approached and cut under aseptic conditions without decerebration and the animal allowed to recover. Complete third nerve paralysis was obtained, but over a period of several months no significant difference in the intra-ocular pressure between the two eyes could be detected. The aplanation tonometer of Maurice (1951) and a Schiötz instrument were used to measure the intraocular pressure.

(3) Stimulation of the Third Nerve.-In all experiments stimulation of the third nerve using 4 volts at $50 \mathrm{cycles} / \mathrm{sec}$. resulted in a rapid rise in intra-ocular pressure accompanied by contraction of the extra-ocular muscles and sphincter pupillae. The rise in intra-ocular pressure was greatest initially, tending to decrease while the stimulus was maintained, but not returning to normal until the stimulation ceased.

In view of the possibility that this rise, which amounted on the average to $5 \mathrm{~cm}$. saline, was due to contraction of the extra-ocular muscles, experiments were carried out with decamethonium iodide to eliminate this factor. Decamethonium iodide paralyses transmission at the neuromuscular junction, in this respect resembling curare. It differs from curare, however, in that it has an initial stimulating action on skeletal muscle and is less effective in producing blockage of transmission in autonomic ganglia (Paton and Zaimis, 1948; 1949).

We found that an average dose of $0.4 \mathrm{mg}$. decamethonium iodide injected intravenously into a rabbit resulted in paralysis of the extra-ocular muscles after an initial tonic contraction. This latter effect had been previously noticed in isolated preparations of the superior rectus muscle in the rabbit (Ambache, 1952). 
In a decerebrated animal the third cranial nerve was stimulated in order to verify that it was intact. $0.4 \mathrm{mg}$. decamethonium iodide was then injected

A
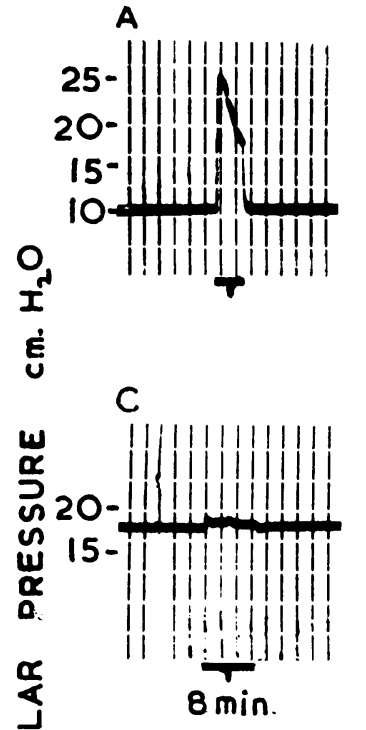

$\mathbf{E}$

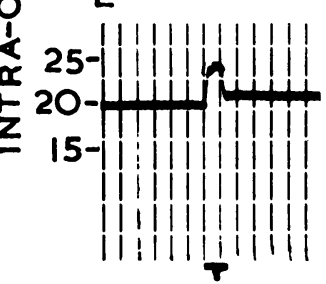

$24 \mathrm{~min}$.
B

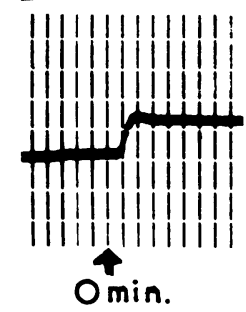

D

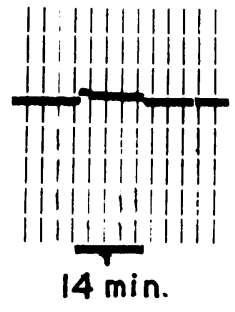

$\mathbf{F}$

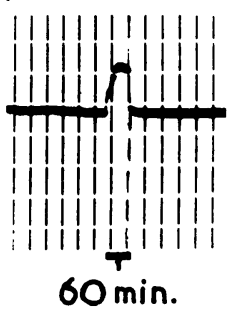

T - Stimulation of IIIrd nerve

4 - Intravenous injection $0.4 \mathrm{mg}$. C 10

Vertical Divisions - 5-second time-marker

FIG. 3.-Recording of intra-ocular pressure in the right eye during stimulation of the right IIIrd nerve.

A, before administration of decamethonium iodide (C10) C, D, E, F, after administration of C10

$B$, effect of intravenous injection of $0.4 \mathrm{mg}$. C10.

Blood pressure remained constant throughout.

intravenously. After an interval of 4 minutes from the injection, stimulation of the third nerve produced good miosis but no contraction of the extra-ocular muscles and no significant change in the intra-ocular pressure (Fig. 3). This experiment was repeated in four other animals with similar results.

It therefore appears that stimulation of the third nerve in normal rabbits has no effect on the intra-ocular pressure except insofar as it causes contraction of the extraocular muscles.

\section{Summary}

(1) Section of the third cranial nerve in rabbits has no significant effect on the intra-ocular pressure.

(2) Stimulation of the same nerve produces a rise in intraocular pressure which is due to contraction of the extraocular muscles.

(3) After paralysis of the extra-ocular muscles by decamethonium iodide, stimulation of the third cranial nerve causes no change in the intra-ocular pressure.

\section{REFERENCES}

Ambache, N. (1952). Personal communication.

ATTREe, V. H. (1950). J. sci. Instrum., 27, 43.

Greaves, D. P., and Perkins, E. S. (1952). British Journal of Ophthalmology, 36, 258.

Henderson, E. E., and Starling, E. H., (1904). J. Physiol., Lond., 31, 305.

MAURICE, D. M. (1951). British Journal of Ophthalmology, 35, 178.

PAton, W. D. M., and Zaimis, E. J. (1948). Nature, Lond., 162, 810.

- (1949). Brit. J. Pharmacol., 4, 381.

Schmerl, E., and SteinberG, B. (1949). Amer. J. Ophthal., 32, 947. 